Background Condyloma acuminata are soft, skin colored, fleshy warts that are caused by the Human Papilloma Virus (HPV), typically HPV 6 and 11 genotypes. The disease is highly contagious, can appear singly, confluent, multiple, small or large. Although anogenital warts are considered to be sexually transmitted in adults, this may not be the case for children. Genital warts in children may result from several modes of transmission: from the maternal genital tract autoinoculation, from finger warts and nonsexual transmission from members/careers. Generally diagnosis of anogenital warts is usually made on physical examination. Surgical treatment options include cryotherapy, laser vaporisation, electrocautery and excision. Nonsurgical approaches in children include the use of podophyllotoxin and imiquimod.

Approach We present a 12-month-old female patient presented with a 6 month history of papillomatosis changes in the anogenital area. The child was born by vaginal delivery after full term normal pregnancy. No maternal medical history of genital warts during her pregnancy. She tested negative for Syphilis at pregnancy.

Physical examination of the child was normal except for the presence of multiple light purple skin-colored, confluent verrucous eruptions affecting the vulva and perianal region (Figure 1). Gynecological examination showed no abnormalities. The hymen was intact, and there was no evidence of ulcerations or other signs of trauma to the vaginal or anal orifices. Biopsy of the lesion was not performed. The girl was treated with 25\% Podophyllotoxin solution, carefully applied at the hospital to the lesions once a week and at every visit, there was evident reduction in the number and size of warts. Treatment was continued for a total of 5 weeks, during which time the lesions cleared almost completely.

Conclusion We conclude from this case that condylomas acuminate are not only transmitted sexually but through nonsexual ways as well, such is this case, from the infected mother to the infant. We also report safe and effective treatment of anogenital warts in a child with regular and carefully applied 25\% Podophyllotoxin solution.

\section{P092 HEALTHCARE ACCESS AND SYPHILIS TESTING AMONG BLACK AND WHITE MSM: RESULTS FROM THE NETWORK EPIDEMIOLOGY OF SYPHILIS TRANSMISSION STUDY}

${ }^{1} \mathrm{C}$ Copen*, ${ }^{*} \mathrm{~J}$ Rushmore, ${ }^{2} \mathrm{~J}$ Jennings, ${ }^{3} \mathrm{~W}$ Miller, ${ }^{3} \mathrm{M}$ Spahnie, ${ }^{2} \mathrm{C}$ Tilchin, ${ }^{3} \mathrm{~A}$ Norris Turner, ${ }^{1} \mathrm{R}$ Kirkcaldy, ${ }^{1} \mathrm{~K}$ Bernstein. ${ }^{1}$ Centers For Disease Control and Prevention, Atlanta, USA; ${ }^{2}$ Johns Hopkins University, Baltimore, USA; ${ }^{3}$ The Ohio State University, Columbus, USA

10.1136/sextrans-2021-sti.221

Background In 2018, men who have sex with men (MSM) accounted for nearly $65 \%$ of newly-reported primary and secondary syphilis cases in the U.S. Syphilis rates are higher among Black than White MSM. Barriers to healthcare access among MSM may contribute to racial disparities in syphilis testing which leads to missed diagnoses. These barriers can be exacerbated by geographic differences in healthcare access. We describe differences in the prevalence of syphilis testing by health insurance status comparing Black to White MSM in two cities (Baltimore, $\mathrm{MD}$ and Columbus, $\mathrm{OH}$ ).
Methods The Network Epidemiology of Syphilis Transmission study enrolled 655 sexually active MSM aged $18+$ from January 2019 through March 2020 ( $\mathrm{n}=329$ Black, $\mathrm{n}=209$ White). At the first study visit, participants were asked about current health insurance status (private or public) and syphilis testing in the 12 months prior to enrollment (yes or no). We used chi-square tests to examine health insurance status and syphilis testing by city comparing Black to White MSM.

Results Although not statistically significant, lower percentages of Black than White MSM in Baltimore had health insurance $(79.6 \%$ vs. $92.4 \%, p=0.11)$, while insurance was universally high in Columbus, regardless of race $(95 \%$, $\mathrm{p}=0.09)$. Lower percentages of Black than White MSM in Baltimore had been tested for syphilis in the past 12 months $(61.7 \%$ vs. $78.7 \%, p=0.06)$, but we observed no testing differences by race in Columbus $(65 \%, p=0.99)$. In Baltimore, fewer insured Black MSM had been tested for syphilis in the last 12 months compared to insured White MSM, but the difference was not significant $(63.4 \%$ vs. $78.7 \%, \mathrm{p}=0.12)$ and was similar in Columbus $(64.9 \%$ vs. $66.4 \%, \mathrm{p}=0.91$ ).

Conclusions Consistent, but non-significant, differences in insurance coverage by race in Baltimore compared with Columbus may indicate geographic variation in healthcare access which can impact timely syphilis testing among MSM.

\section{P093 IMPACT OF COVID-19 HARD LOCKDOWN MEASURES ON SEXUAL BEHAVIOUR IN VICTORIA, AUSTRALIA: FINDINGS FROM A NATIONAL ONLINE SURVEY}

'f Coombe*, 'f Goller, ${ }^{1} \mathrm{H}$ Bittleston, ${ }^{1} \mathrm{~F}$ Yuh Shiong Kong, ${ }^{1,2}{ }^{2}$ Williams, ${ }^{3} \mathrm{~J}$ Tomnay, ${ }^{1} \mathrm{~A}$ Vaisey, ${ }^{1,4} \mathrm{~S}$ Malta, ${ }^{5} \mathrm{M}$ Temple-Smith, 'L Bourchier, ${ }^{1} \mathrm{~A}$ Lau, ${ }^{1,2,6} \mathrm{E}$ Chow, ${ }^{1 J} \mathrm{H}$ Hocking. ${ }^{1}$ Melbourne School of Population and Global Health, The University of Melbourne, Melbourne, Australia; ${ }^{2}$ Melbourne Sexual Health Centre, Carlton, Australia; ${ }^{3}$ Centre for Excellence in Rural Sexual Health, Department of Rural Health, The University of Melbourne, Melbourne, Australia; ${ }^{4}$ National Ageing Research Institute Inc, Parkville, Australia; ${ }^{5}$ Department of General Practice, The University of Melbourne, Melbourne, Australia; ${ }^{6}$ Central Clinical School, Monash University, Melbourne, Australia

\subsection{6/sextrans-2021-sti.222}

Background The residents of Victoria (Australia's second most populous state), were subject to a hard lockdown for several months as they experienced a second wave of COVID-19. Victorians could only leave their homes for essential activities, were required to wear facemasks, remain within $5 \mathrm{~km}$ of their homes and were subject to a nightly curfew. Elsewhere in Australia, COVID numbers remained low with no lockdown in place. We examined the impact of the lockdown on the sexual behaviour of Victorians compared with elsewhere in Australia.

Methods Our online survey was open for 2.5 weeks during the lockdown (August 13th to 31st). Participants aged $18+$ were recruited via social media and asked to report on their current sexual practices. Logistic regression was used to calculate the difference in the proportion of practices between Victorians and non-Victorians.

Results 976 people completed the survey: 71\% identified as female, $75 \%$ were aged 18-29 years, 61\% resided in 